\title{
Grower Risk Aversion and the Cost of Moral Hazard in Livestock Production Contracts
}

\author{
Pierre Dubois*and Tomislav Vukina ${ }^{\dagger}$
}

November $2003^{\ddagger}$

\begin{abstract}
This paper develops an analytical framework for the econometric estimation of the degree of risk aversion of contract growers in the livestock industry and carries out its empirical estimation using micro level performance data in the case of hog production. We show how the individual heterogeneity affects the allocation of contracted quantities across growers. This information is used to estimate the cost of moral hazard that integrator companies are exposed to and the amount of risk premium that growers are indirectly paying to the integrators for the provision of income volatility insurance.
\end{abstract}

Keywords: Agency Contracts, Moral Hazard, Risk Aversion.

JEL Classification: D82, L24, Q12, K32, L51.

\footnotetext{
${ }^{*}$ University of Toulouse (INRA, IDEI)

$\dagger$ North Carolina State University

${ }_{\ddagger}$ We are thankful to Laura Martin for the permission to use her contract settlements data set.
} 


\section{Introduction}

The use of contracts to vertically coordinate the production and marketing of agricultural commodities has become common practice in many agricultural sectors. The notable examples are the production of chickens, turkeys and hogs. To solve the apparent asymmetric information problems between processors and independent farmers that universally plague these relationships, the majority of contracts use high powered incentives schemes to compensate farmers. In light of the renewed interest and increased pressure on the States and Federal government to regulate livestock production contracts, a legitimate question to ask is how much are the producers going to loose if forced to replace the high powered incentives schemes that include performance bonuses with some low powered ones such as simple piece rates. The answer to this question depends on the ability of researchers to measure the magnitude of the cost of moral hazard.

The welfare cost of moral hazard emanates from the fact that contract growers are risk averse and face uncertain income streams. The degree of risk aversion generates more or less disutility from uncertainty and plays an important role in the design of the optimal contract form. The literature on the provision of incentives in firms is based on the premise that relating pay to performance increases output, but at the cost of imposing risk on the agents, which is reflected in higher compensations. Grower welfare depends on the type of contract he has signed, the distribution of random factors affecting production and the shape of his utility function.

The objective of this paper is to develop an analytical framework for the econometric estimation of the degree of risk aversion of farmers involved in the contract production of hogs and to carry out the empirical estimation of the individual risk aversion parameters using micro level contract performance data. These estimates are subsequently used to assess the cost of moral hazard caused by growers risk aversion that affects both the processor and the contract producers.

The attempts to quantify the welfare losses associated with moral hazard and risk 
aversion in different fields of the economy are few and recent. For example, Ferrall and Shearer (1999) estimated the cost of incomplete information due to insurance (worker risk aversion) and incentives consideration and found that the two costs are of similar magnitudes. In the context of managerial compensation, Margiotta and Miller (2000) found that the costs of aligning hidden managerial actions to shareholders' goals through the compensation schedule are much less than the benefits from the resulting managerial performance. Similar to our model, heterogeneity in agents' risk preferences is also found in Paarsch and Shearer (2000). They estimated a structural model with moral hazard in the context of tree-planting labor contracts and found that incentives caused a 22.6 percent increase in productivity, only a part of which represents valuable output because workers respond to incentives by reducing quality.

Our results show that growers are heterogeneous when it comes to comparing their risk aversion parameters and that risk aversion heterogeneity affects the principal's allocation of contracted quantities across growers. The results provide a strong empirical support for the central tenet of the agency theory that contracts are designed to optimally trade-off risk sharing against incentives provision.

Our paper contributes importantly to the resolution of two related controversies; one found in the empirical work on contract choice, and the other in the literature on testing the trade-off between risk and incentives. When it comes to the determination of contract choice, the transaction cost literature (e.g., Allen and Lueck, 1992) claims the unimportance of risk. On the other hand, Ackerberg and Botticini (2002) showed that if one controls for the endogenous matching between principals and agents, the agent's risk aversion appears to significantly influence the contract choice. When it comes to testing whether risk imposes a constraint to offering incentives the evidence is also mixed, with some work finding evidence in favor of the theories, while other find little (Prendergast, 1999). 


\section{Industry Description and Data}

Swine production in the United States is characterized by an increasing presence of vertically integrated firms (called integrators) that contract the production (grow-out) of hogs with independent farmers. The contract production is dominated by large national companies (Smithfield Foods, Premium Standard Farms, etc.,) which run their businesses through smaller profit centers that issue contracts, supply inputs and slaughter finished animals.

A production contract is an agreement between an integrator company and a farmer (grower) that binds the farmer to specific production practices. Different stages of production of animals are typically covered by different contracts and farmers generally specialize in the production of animals under one contract. The most frequently observed contracts in the swine industry are single production stage contracts such as farrowing contracts, nursery contracts and especially finishing contracts. All production contracts have two main components: one is the division of responsibility for providing inputs, and the other is the method used to determine grower compensation. Growers provide land, housing facilities, utilities (electricity and water) and labor and are also responsible for manure management and disposal of dead animals. An integrator company provides animals, feed, medications and services of field men. Companies also own and operate feed mills and processing plants and provide transportation of feed and live animals. The integrator also decides on the volume of production both in terms of the rotations of batches on a given farm and the density of animals inside the house. A typical scheme for compensating growers in finishing contracts is based on a base plus bonus payment per pound of gain (live weight) transferred, where a bonus payment reflects some efficiency measure such as feed conversion.

The data set used in this study is an unbalanced panel from Martin (1997). It contains a sample of contract settlement data for individual growers who contracted the finishing stage of hog production with an integrator in North Carolina. The data set 
spans the period between December 1985 and April 1993, for a total of 802 observations. Each observation represents one contract realization, i.e., the payment received and the grower performance associated with one batch of animals delivered to the integrator's processing plant. There are 122 growers in the data set and the number of observations per grower ranges from 2 to $37 .^{1}$

The size of the grow-out operation (the number of finishing houses) varies across growers between one and five houses. All houses under contract have approximately the same capacity. The median density of a house is 1,226 hogs per house and the mean density is 1,234 hogs per house. The contract coverage varies across farms and time. Sometimes one contract will cover multiple houses on a given farm, other times each house will be covered by a separate contract. In cases when multiple houses are covered by one contract, the grower payment is calculated by treating all houses as one unit. The coverage of the contract is determined by the timing of the placement and genetic composition of feeder pigs. The animals covered by the same contract have to be placed on a given farm at the same time and have to have similar genetic characteristics. ${ }^{2}$ The average length of the production cycle is approximately 19 weeks. Counting one additional week for the necessary cleanup gives a maximum of 2.6 batches of finished hogs per house per year. The data summary statistics are presented in Table 1.

The particular finishing contract that generated the data is fairly representative for the industry as a whole. The contract requires that growers furnish fully equipped housing facilities and that they follow the management and husbandry practices specified by the integrator. The contract guarantees the grower a minimum of 7 batches of feeder pigs and is automatically renewed unless cancelled in writing. The integrator provides

\footnotetext{
${ }^{1}$ The reasons for unequal number of observations across growers is unknown. We confidently rule out the possibility that the facilities of those growers with only few observations in the data set were predominantly idle during that period. It appears that the data sample has been extracted randomly from the population of all contracts that has been settled between this integrator and her growers during this time period.

${ }^{2}$ As a consequence, we occasionally encounter more than one observation per grower $i$ in period $t$.
} 
the grower with feeder pigs, feed, medication, veterinary services and services of the field personnel. The quality of all inputs as well as the time of placement of feeder pigs and shipment of grown animals are exclusively under control of the integrator.

\section{Table 1: Descriptive Statistics}

\begin{tabular}{lcc}
\hline \hline Variable & Mean & Std. Deviation \\
\hline Feed conversion ratio $\left(f_{i t}\right)$ & 2.76 & 0.151 \\
Grower's revenue in US\$ $\left(R_{i t}\right)$ & 18886 & 10022 \\
Heads placed $\left(H_{i t}\right)$ & 2077 & 1111 \\
Mortality rate $\left(m_{i t}\right)$ & 0.039 & 0.020 \\
Feed used in $(1000)$ pounds $\left(F_{i t}\right)$ & 1033 & 553 \\
Weight gained in $(1000)$ pounds $\left(q_{i t}\right)$ & 373 & 195 \\
\hline \hline
\end{tabular}

The compensation to grower $i$ for the batch of hogs under contract $t$ as the payment for husbandry services and the housing facilities rental is calculated on a per pound of gain basis with bonuses earned on a per head basis. The bonus is based on the difference between the individual grower's feed conversion, expressed as pounds of feed divided by pounds of gain $\frac{F_{i t}}{q_{i t}}$, and a standard feed conversion ratio $\phi$. If the grower's ratio is above the standard, he receives no bonus and simply earns the base piece rate $\alpha$ multiplied by the total pounds gained $q_{i t}$. If the grower's ratio is below the standard ratio, the difference is multiplied by a constant $\beta$ to determine the per head bonus rate. The total bonus payment is then determined by multiplying the bonus rate by the number of pigs marketed, where the marketed pigs $\left(1-m_{i t}\right) H_{i t}$ are those feeder pigs that survived the fattening process and $m_{i t}$ is the grower-specific animal mortality rate. Mathematically, the exact formula for the total compensation is:

$$
R_{i t}=\alpha q_{i t}+\max \left[0, \beta\left(\phi-\frac{F_{i t}}{q_{i t}}\right)\left(1-m_{i t}\right) H_{i t}\right]
$$

During the period covered by the data set some parameters of the payment mechanism (1) have changed. The base piece rate varied with the type of feeder pigs placed 
on a grower farm. For commingled feeder pigs $\alpha=0.0315$, whereas for integrator's own nursery feeder pigs $\alpha=0.0275 .^{3}$ Also, as a result of technological progress in nutrition and housing design, the feed conversion standard was lowered from $\phi=3.50$ to $\phi=3.35$. However, after the lower feed conversion standard was introduced, the higher standard of 3.50 remained in effect for commingled pigs. Consequently, we have three different payment schemes: $(\alpha=0.0315, \phi=3.50),(\alpha=0.0275, \phi=3.50)$ and ( $\alpha=0.0275, \phi=3.35$ ). All observed feed conversion ratios are below the benchmark feed conversion $(\phi)$, so the truncation of the bonus payment at zero can be harmlessly ignored and the payment scheme simplified as

$$
R_{i t}=\alpha q_{i t}+\beta\left(\phi-\frac{F_{i t}}{q_{i t}}\right)\left(1-m_{i t}\right) H_{i t}
$$

\section{The Model}

We model the integrator-grower relationship in a principal-agent framework. The agent (grower) is required to perform specific tasks that are not perfectly observable by the integrator (principal), who therefore faces a moral hazard problem in the delegation of production tasks. The incentives to the grower to behave according to the principal's objective are provided through the payment scheme which always includes a particular type of bonus (premium) mechanism. In our contract the bonus depends on a perfectly observable and verifiable performance measure which is the feed conversion ratio. Ignoring the issues related to the contract design, we first model the agent's behavior given the terms specified in the observed contract. Then, we study the principal's behavior given the agent's optimal response.

We assume that growers preferences over revenue $R$ and effort $e$ are described by the utility function $U_{i}(R-C(e))$ which is public and observed by the Principal. $C($.$) is a$

\footnotetext{
${ }^{3}$ There are three types of feeder pigs in the data set. Commingled pigs are feeder pigs that are either bought at an auction or from an outside source. The third type are own feeder pigs which come from the breeding stock controlled by the integrator, hence are deemed to be of superior quality.
} 
positive increasing function implying that effort is costly. We assume that growers exhibit constant absolute risk aversion (CARA) and that the stochastic revenue is normally distributed. Under these assumptions, grower $i$ 's expected utility can be expressed as an increasing concave function of a mean-variance criterium (which corresponds to the certainty equivalent value of revenue) and his maximization problem can be written as:

$$
\max _{e} W_{i}(R, e)=E R-\frac{b_{i}}{2} \operatorname{Var} R-C(e)
$$

where the coefficient $b_{i}>0$ measures the absolute risk aversion. ${ }^{4}$

First, we can write the payment scheme in (2) as a linear function of the performance measure, i.e. the feed conversion ratio $f_{i t}=\frac{F_{i t}}{q_{i t}}$, such that

$$
R_{i t}=\tilde{\alpha}_{i t}-\tilde{\beta}_{i t}\left(f_{i t}-\phi\right)
$$

where

$$
\begin{aligned}
& \tilde{\alpha}_{i t}=\alpha q_{i t}=\alpha\left[\kappa_{i t}\left(1-m_{i t}\right)-\kappa_{0 i t}\right] H_{i t} \\
& \tilde{\beta}_{i t}=\beta\left(1-m_{i t}\right) H_{i t}
\end{aligned}
$$

with $\kappa_{i t}$ being the weight of outgoing finished hogs and $\kappa_{0 i t}$ the weight of incoming feeder pigs. We assume that the parameters of this affine function are fixed at the time the grower chooses his effort. ${ }^{5}$

Next, we specify how the observed outcome stochastically depends on the unobservable grower effort and assume that

$$
f_{i t}-\phi=\left(\lambda_{i}-e_{i t}\right) u_{i t}
$$

\footnotetext{
${ }^{4}$ Notice that the curvature of the utility function is grower-specific which allows much more flexibility than when the curvature is common to all agents, i.e. when $b_{i}$ is constant.

${ }^{5}$ The assumption that the parameters $\tilde{\alpha}_{i t}$ and $\tilde{\beta}_{i t}$ depend on conditions and variables known and observed by the grower when he chooses his effort is reasonably realistic. First, the grower always observes the number $H_{i t}$ and the weight $\kappa_{0 i t}$ of feeder pigs when they arrive on the farm. The grower also knows that the pigs are grown until they reach their target weight $\kappa_{i t}$. Finally, the grower can accurately judge the mortality rate $m_{i t}$ by observing the genetic make-up and the overall condition of feeder pigs delivered to the farm and the density at which they are stocked.
} 
where $\lambda_{i}$ reflects some fixed ability parameter of grower $i, e_{i t}$ is the costly effort which improves (reduces) the feed conversion ratio, and $u_{i t}$ is an i.i.d. (across growers and periods) production shock with mean 1 and variance $\sigma^{2}$. This specification shows that a unit of effort is worth one unit of feed conversion ratio which gets transformed into revenue through $\tilde{\beta}_{i t}$. Since the cost of effort is monetary, it must be in the same units as revenue, hence we specify

$$
C\left(e_{i t}\right)=\gamma \tilde{\beta}_{i t} e_{i t}
$$

where $0<\gamma<1 .^{6}$

Now, using (4) and (6) we can write the agent's certainty equivalent net revenue as

$$
W_{i}\left(R_{i t}, e_{i t}\right)=\tilde{\alpha}_{i}-\tilde{\beta}_{i t}\left[E f_{i t}-\phi\right]-\frac{b_{i}}{2} \tilde{\beta}_{i t}^{2} \operatorname{Var}\left[f_{i t}\right]-\gamma \tilde{\beta}_{i t} e_{i t}
$$

and the first order condition for the maximization problem in (3) becomes

$$
\gamma=-\frac{\partial}{\partial e_{i t}} E f_{i t}-\frac{b_{i}}{2} \tilde{\beta}_{i t} \frac{\partial}{\partial e_{i t}} \operatorname{Var}\left[f_{i t}\right]
$$

Given (6), it is clear that

$$
\begin{aligned}
E f_{i t}-\phi & =\lambda_{i}-e_{i t} \\
\operatorname{Var}\left[f_{i t}\right] & =\left(\lambda_{i}-e_{i t}\right)^{2} \sigma^{2}
\end{aligned}
$$

which gives the following expression for the optimal effort level:

$$
e_{i t}^{*}=\frac{1-\gamma}{\sigma^{2} b_{i} \tilde{\beta}_{i t}}+\lambda_{i}
$$

As standard in incentive problems, equation (7) reveals that more risk averse growers, i.e. those with higher $b_{i}$, exert lower equilibrium effort, and also that stronger incentives power $\left(-\tilde{\beta}_{i t}\right)$ increases effort. This result has an important consequence for the equilibrium strategy that the integrator would pursue when it comes to deciding how to allocate feeder pigs among growers with different risk aversion attitudes.

\footnotetext{
${ }^{6}$ Notice that the apparently more general specification $f_{i t}-\phi=\left(\lambda_{i}-\rho e_{i t}\right) u_{i t}$ is not different from the chosen one because we could simply redefine effort as $\widetilde{e}_{i t}=\rho e_{i t}$ whose cost will be $\frac{\gamma}{\rho} \tilde{\beta}_{i t} \widetilde{e}_{i t}$ instead of $\gamma \tilde{\beta}_{i t} e_{i t}$.
} 
Now, we model the principal's behavior given the agent's optimal response. As is customary, we assume that the principal is risk neutral and maximizes the expected profit per grower by deciding how many feeder pigs to place on a grower's farm. The integrator's objective function is

$$
\max _{H_{i t}} E \pi_{i t}=E\left[p Q_{i t}-R_{i t}-w_{F} F_{i t}-w_{H} H_{i t}\right]
$$

where $p$ is the market price of hogs, $Q_{i t}=\kappa_{i t}\left(1-m_{i t}\right) H_{i t}$ is the total live weight removed from the grower's farm, $R_{i t}$ is grower payment as specified in $(2), w_{F}$ is the market price of feed and $w_{H}$ is the market price of feeder pigs.

Using (4) and the optimal grower effort (7), the integrator's expected profit becomes

$$
\begin{aligned}
E \pi_{i t}= & p \kappa_{i t}\left(1-m_{i t}\right) H_{i t}-w_{F}\left(\frac{\gamma-1}{\tilde{\beta}_{i t} \sigma^{2} b_{i}}+\phi-\frac{\alpha}{w_{F}}\right)\left[\kappa_{i t}\left(1-m_{i t}\right)-\kappa_{0 i t}\right] H_{i t}-w_{H} H_{i t} \\
= & {\left[p-w_{F}\left(\phi-\frac{\alpha}{w_{F}}\right)\right] \kappa_{i t}\left(1-m_{i t}\right) H_{i t}+w_{F} \frac{(\gamma-1) \kappa_{0 i t}}{\beta\left(1-m_{i t}\right) \sigma^{2} b_{i}} } \\
& +\left[w_{F}\left(\phi-\frac{\alpha}{w_{F}}\right) \kappa_{0 i t}-w_{H}\right] H_{i t}-w_{F} \frac{(\gamma-1) \kappa_{i t}}{\beta \sigma^{2} b_{i}} .
\end{aligned}
$$

It is intuitively obvious that the number of animals placed on a grower's farm cannot be infinite given that the housing facilities are of finite size. The mortality rate will be increasing and necessarily approaching $100 \%$ when $H$ approaches infinity. This implies that profits will obtain a maximum for $H<\infty$. To simplify, we assume that the mortality rate function $m_{i t}\left(H_{i t}\right)$ is such that the profit function has a unique maximum and do the following assumption:

- Assumption: $m_{i t}\left(H_{i t}\right)$ is increasing concave with $m^{\prime \prime}(1-m)+2 m^{\prime 2} \geq 0$ and $2 m^{\prime}+m^{\prime \prime} H>0$.

For example, this assumption is satisfied on ${ }^{7}[0,2 \eta]$ with a mortality rate function

$$
m_{i t}\left(H_{i t}\right)=1-\exp -\frac{H_{i t}}{\eta} ; \text { with } \eta>0
$$

\footnotetext{
${ }^{7}$ In fact, the condition $2 m^{\prime}+m^{\prime \prime} H>0$ is satisfied in this case if $H_{i t}<2 \eta$. We will check empirically that $\eta$ is sufficiently large compared to the range of values of $H$.
} 
Now we are in the position to state the following result.

Proposition: The optimal $H_{i t}^{*}\left(b_{i}\right)$ chosen by the integrator is such that $H_{i t}^{* \prime}\left(b_{i}\right)<0$, which means that more risk averse growers will receive fewer animals.

Proof: The first order condition for the integrator's expected profit maximization is

$$
\begin{aligned}
0= & {\left[p-w_{F}\left(\phi-\frac{\alpha}{w_{F}}\right)\right] \kappa_{i t}\left(\frac{\partial}{\partial H_{i t}}\left[\left(1-m_{i t}\left(H_{i t}^{*}\right)\right) H_{i t}^{*}\right]\right) } \\
& +w_{F} \frac{(\gamma-1) \kappa_{0 i t}}{\beta \sigma^{2} b_{i}} \frac{m_{i t}^{\prime}\left(H_{i t}^{*}\right)}{\left(1-m_{i t}\left(H_{i t}^{*}\right)\right)^{2}}+\left[w_{F}\left(\phi-\frac{\alpha}{w_{F}}\right) \kappa_{0 i t}-w_{H}\right]
\end{aligned}
$$

from which it follows that $H_{i t}^{*}\left(b_{i}\right)$ is a solution of the following implicit equation

$$
\frac{\partial}{\partial H_{i t}}\left[\left(1-m_{i t}\left(H_{i t}^{*}\left(b_{i}\right)\right)\right) H_{i t}^{*}\left(b_{i}\right)\right]=\Psi\left(b_{i}, H_{i t}^{*}\left(b_{i}\right)\right)
$$

where

$$
\Psi\left(b_{i}, H_{i t}^{*}\right)=\frac{\left[w_{H}-w_{F}\left(\phi-\frac{\alpha}{w_{F}}\right) \kappa_{0 i t}\right]-w_{F} \frac{(\gamma-1) \kappa_{0 i t}}{\beta \sigma^{2}} \frac{1}{b_{i}} \frac{m_{i t}^{\prime}\left(H_{i t}^{*}\right)}{\left(1-m_{i t}\left(H_{i t}^{*}\right)\right)^{2}}}{\left[p-\phi w_{F}+\alpha\right] \kappa_{i t}} .
$$

Taking derivatives of the first order condition gives

$$
\begin{gathered}
H_{i t}^{* \prime}\left(b_{i}\right) \frac{\partial^{2}}{\partial H_{i t}}\left[\left(1-m_{i t}\left(H_{i t}^{*}\left(b_{i}\right)\right)\right) H_{i t}^{*}\left(b_{i}\right)\right]=\frac{\partial}{\partial b_{i}} \Psi\left(b_{i}, H_{i t}^{*}\left(b_{i}\right)\right)+H_{i t}^{* \prime}\left(b_{i}\right) \frac{\partial}{\partial H_{i t}} \Psi\left(b_{i}, H_{i t}^{*}\left(b_{i}\right)\right) \\
H_{i t}^{* \prime}\left(b_{i}\right)\left[\frac{\partial^{2}}{\partial H_{i t}}\left[\left(1-m_{i t}\left(H_{i t}^{*}\left(b_{i}\right)\right)\right) H_{i t}^{*}\left(b_{i}\right)\right]-\frac{\partial}{\partial H_{i t}} \Psi\left(b_{i}, H_{i t}^{*}\left(b_{i}\right)\right)\right]=\frac{\partial}{\partial b_{i}} \Psi\left(b_{i}, H_{i t}^{*}\left(b_{i}\right)\right) .
\end{gathered}
$$

It is clear that $\frac{\partial}{\partial b_{i}} \Psi\left(b_{i}, H_{i t}^{*}\left(b_{i}\right)\right)>0$ and $\frac{\partial^{2}}{\partial H_{i t}}\left[\left(1-m_{i t}\left(H_{i t}^{*}\left(b_{i}\right)\right)\right) H_{i t}^{*}\left(b_{i}\right)\right]<0$ because the function $m_{i t}$ is increasing concave. ${ }^{8}$ The assumption that $m^{\prime \prime}(1-m)+2 m^{\prime 2} \geq 0$ implies that $\frac{\partial}{\partial H_{i t}} \Psi\left(b_{i}, H_{i t}^{*}\left(b_{i}\right)\right)>0$ and therefore $H_{i t}^{* \prime}\left(b_{i}\right)<0$. Actually, $\frac{\partial}{\partial H_{i t}} \Psi\left(b_{i}, H_{i t}^{*}\left(b_{i}\right)\right)$ is of the sign of $\frac{\partial}{\partial H_{i t}} \frac{m_{i t}^{\prime}\left(H_{i t}^{*}\right)}{\left(1-m_{i t}\left(H_{i t}^{*}\right)\right)^{2}}=\frac{\left.m_{i t}^{\prime \prime}\left(H_{i t}^{*}\right)\left(1-m_{i t}\left(H_{i t}^{*}\right)\right)+2 m_{i t}^{\prime 2}\left(H_{i t}^{*}\right)\right)}{\left(1-m_{i t}\left(H_{i t}^{*}\right)\right)^{3}}$ which is positive if $m^{\prime \prime}(1-$ $m)+2 m^{\prime 2} \geq 0$.

\section{Estimation and Empirical Results}

Using the panel data described before, we can now estimate the structural model we developed so far. Substituting (7) in (6) yields the formula for the difference between

${ }^{8}$ Actually, $\frac{\partial^{2}}{\partial H_{i t}}\left[\left(1-m_{i t}\left(H_{i t}\right)\right) H_{i t}\right]=-2 m_{i t}^{\prime}-m_{i t}^{\prime \prime} H_{i t}<0$ by assumption. 
the benchmark feed conversion and the equilibrium feed conversion

$$
\phi-f_{i t}^{*}=\frac{1-\gamma}{\tilde{\beta}_{i t} \sigma^{2} b_{i}} u_{i t}
$$

which by taking logs gives the following equation

$$
\ln \left(\left(\phi-f_{i t}\right) \tilde{\beta}_{i t}\right)=\ln \left(\frac{1-\gamma}{\sigma^{2}}\right)-\ln \left(b_{i}\right)+\ln \left(u_{i t}\right) .
$$

The individual level parameters $b_{i}$ in (11) can be estimated with a linear regression including growers fixed effects. Notice, however, that $b_{i}$ 's are identified only up to scale since $\ln \left(\frac{1-\gamma}{\sigma^{2}}\right)-\ln \left(b_{i}\right)=\ln \left(\frac{1-\gamma}{\sigma^{2}} \lambda\right)-\ln \left(b_{i} \lambda\right)$ for any $\lambda>0$. Nevertheless, once the estimates of $b_{i}$ are known, one can test for the heterogeneity of risk aversions across growers.

The estimation of (11) shows that the unexplained variance accounts for around $50 \%$ of the total variance. An $F$ test that all $\ln \left(b_{i}\right)$ are equal strongly rejects the homogeneity of growers with respect to their risk aversion $(F(121,680)=5.34)$. The distribution of risk aversion parameters $b_{i}$ displayed in Figure 1 is characterized by the fact that the median risk aversion is $43 \%$ higher than the value of the $25^{\text {th }}$ percentile of the distribution and $21 \%$ lower than the value of the $75^{t h}$ percentile of the distribution. These measures are independent of the scale of coefficients and show substantial heterogeneity across growers regarding their risk aversion.

Our next objective is to test whether the theoretical implications of the model are consistent with the data. Using the structural estimates of risk aversion parameters $b_{i}$ we want to test the main proposition of the paper that more risk averse growers receive fewer animals. We first check whether the sufficient conditions on the mortality function $m_{i t}\left(H_{i t}\right)$ are satisfied. The data does not allow us to estimate function $m($.$) and its first$ and second derivatives non-parametrically because the sample size is not large enough for such a demanding estimation but one can use the parametric form (9) for mortality from which it follows that

$$
H_{i t}=-\eta \ln \left(1-m_{i t}\right)
$$

and then estimate parameter $\eta$ by least squares. The results show that $\widehat{\eta}=26,300$ (with the standard error of 445) and the functional fit is quite good with $R^{2}=79 \%$. 
Figure 1: Distribution of Estimated $b_{i}$

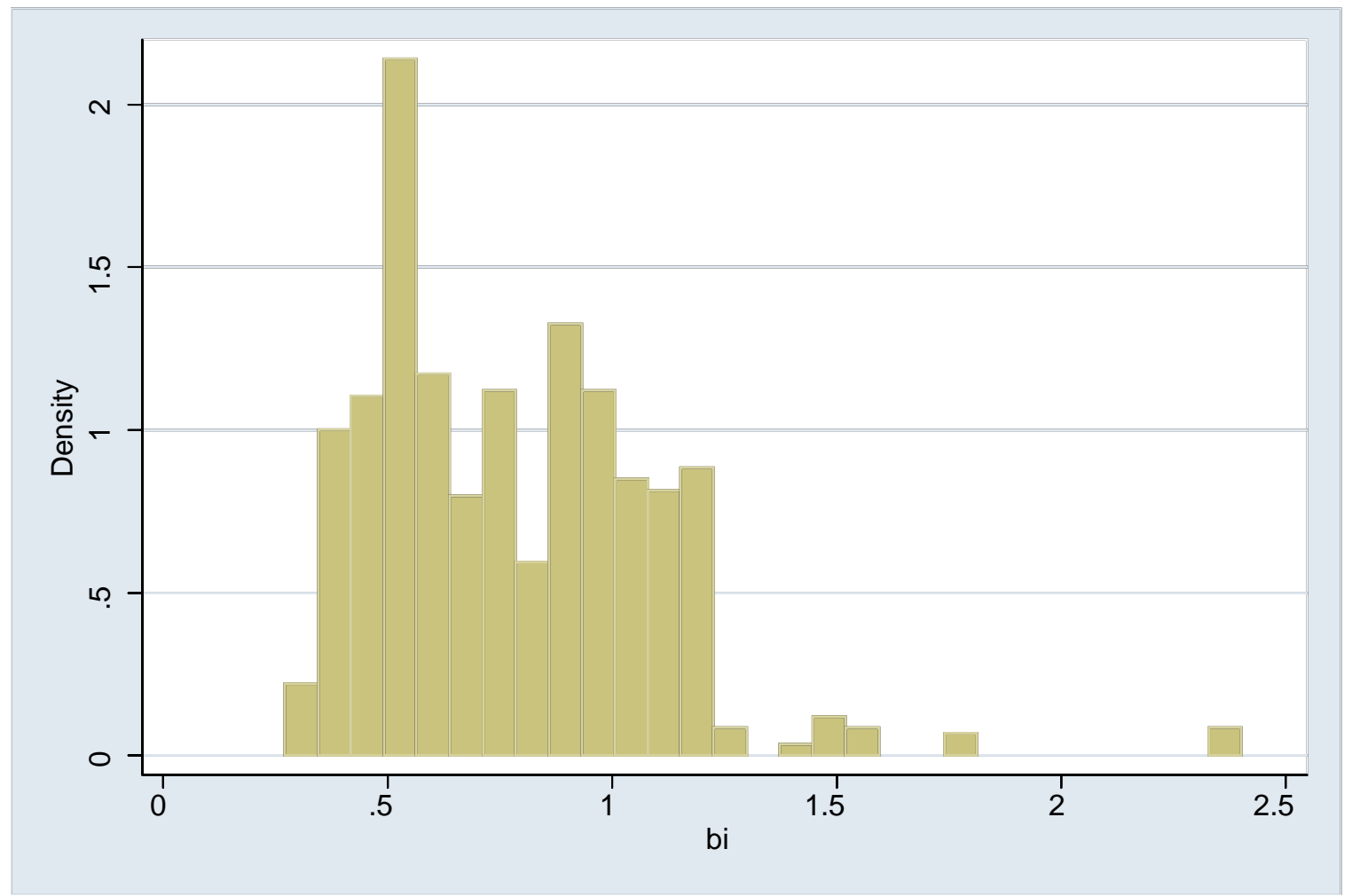

When estimating $\eta$ 's that vary across feeder pigs type, the $R^{2}$ goes up to $85 \%$ while the estimates of $\eta$ are 26,000 (s.e. 638); 27,300 (s.e. 724); and 15,100 (s.e. 708). Notice that for the mortality function in (9), the assumption that led to our Proposition, i.e., $2 m^{\prime}+m^{\prime \prime} H>0$ is satisfied if $H<2 \eta$. Since the observed values of $H_{i t}$ are between 1,100 and 1,500 per house, this condition is easily satisfied. Then, one can test whether the integrator supplies more feeder pigs to less risk averse growers by looking into the relationship between $H_{i t}$ and $b_{i}$.

First, a non-parametric test of independence between $H_{i t}$, or the average over contracts of $H_{i t}$ for grower $i$, and $b_{i}$ shows that independence is strongly rejected. The Spearman rank correlation coefficient is negative and strongly significant. Next, a nonparametric estimate of $E\left(H_{i t} \mid b_{i}\right)$ obtained by using a standard kernel regression method 
(shown in Figure 2) clearly indicates that $E\left(H_{i t} \mid b_{i}\right)$ is a strictly decreasing function of $b_{i}$, and so does a linear regression model (whose results are not reported here).

Figure 2: Non parametric estimate of $E\left(H_{i t} \mid b_{i}\right)$

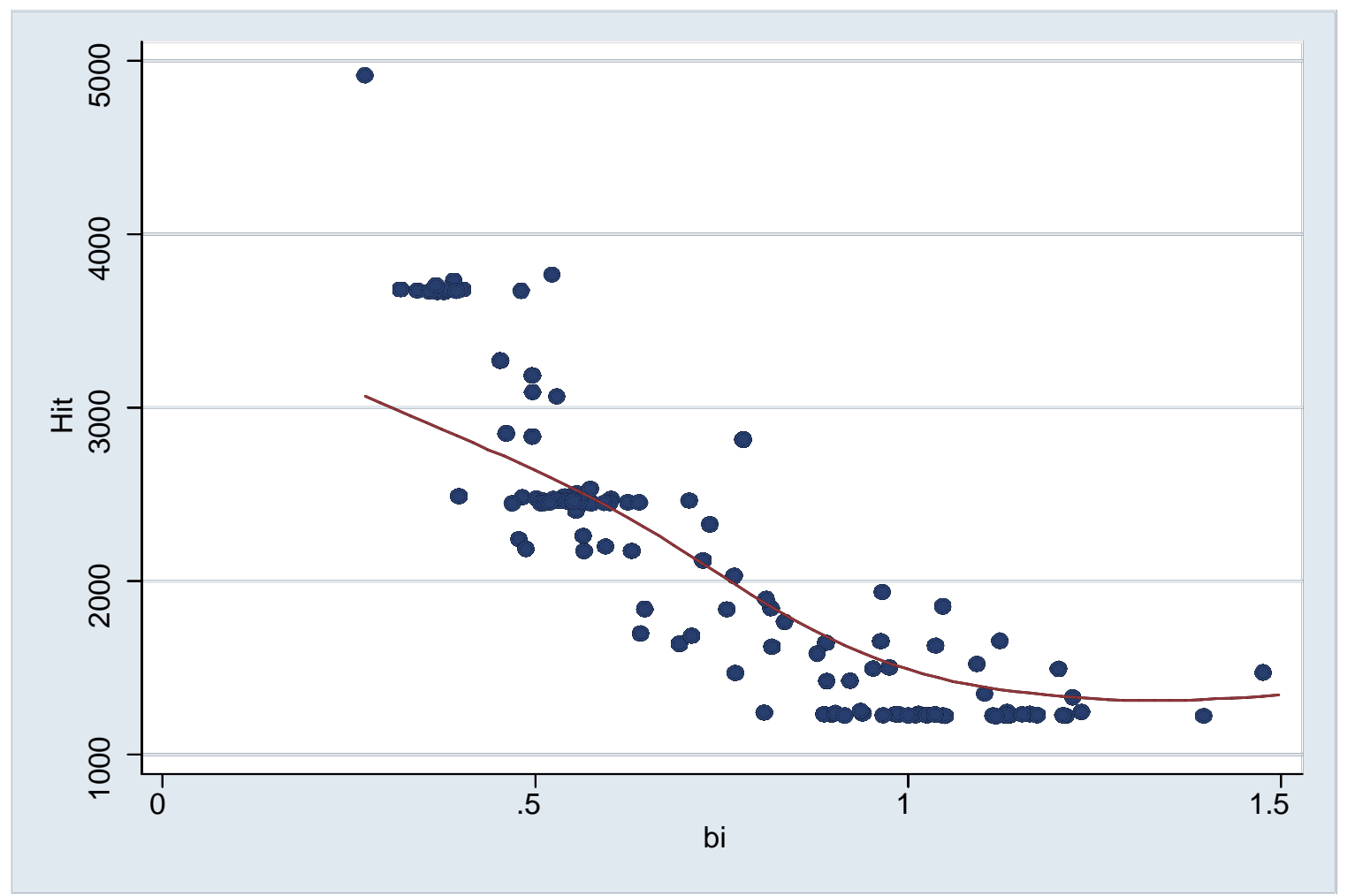

Next, although the scale of risk aversion is not identified, the elasticity of the number of animals placement with respect to risk aversion is uniquely identified. A non parametric estimation of $E\left(\ln H_{i t} \mid \ln b_{i}\right)$ shows that the function is linear and the linear regression gives the estimate $\frac{\partial E\left(\ln H_{i t} \mid \ln b_{i}\right)}{\partial \ln b_{i}}=-0.84$ with a robust standard error of 0.02 . This result shows that a $10 \%$ increase in absolute risk aversion results in a $8.4 \%$ decrease in the number of animals that the integrator would place on the grower's farm.

Finally, we look at the cost of moral hazard associated with growers' risk aversion. The volatility of income in production contracts constitutes a direct real cost to growers and can be thought of as the cost of moral hazard in the sense that without moral haz- 
ard, integrators could pay growers constant wages to compensate them for their effort in case effort were observable and verifiable. However, obtaining welfare estimates of the cost of moral hazard is impossible because the marginal cost of effort and the absolute risk aversion are not identified. Nevertheless, it is interesting to look at the relationship between the mean and the variance of growers' revenues and their risk aversion parameters. First, $60 \%$ of the variance of total payments to growers $R_{i t}$ is explained by the between-growers variance. Second, a linear regression shows a significant negative relationship between the within-grower variance (estimated for each grower along the time dimension of the panel data) and risk aversion. Also, the mean payment is significantly decreasing with risk aversion. The grower level variability of income is such that the average standard deviation is $\$ 3,960$ with a median of $\$ 2,856$. The above results point out that the cost of moral hazard to growers is substantial.

Moreover, it is important to note that the costs of asymmetric information arise not only from the fact that part of the performance risk (in terms of feed conversion) has to be borne by growers (because they have to be given the correct incentives to perform), but also from the fact that the integrator allocates different number of animals to different growers according to their risk aversions. We anticipate that more risk averse growers would have lower revenues because, ceteris paribus, they perform worse in terms of the feed conversion ratio (which reduces their bonus payment), but also because they receive fewer animals compared to the less risk averse growers.

Notice however that the relationship between grower risk aversion and his expected revenue is theoretically ambiguous. Looking at the equilibrium effort equation (7), it follows that the optimal effort decreases with higher risk aversion but also with $\tilde{\beta}$ and hence $H_{i t}$. Therefore, since more risk averse growers received fewer animals, the overall comparative statics effect of risk aversion on the optimal effort and hence on the expected revenue is undetermined.

The empirical results show that the revenues of more risk-averse growers are less volatile but, also, on average lower. Table 2 shows the average of the means and standard 
deviations of each grower's revenue $R_{i t}$ for different percentiles of the distribution of $b_{i}$. Except for the 50-60 percentiles of the distribution, the relationship shows a negative link between the mean and the variance of grower revenue and risk aversion. This empirical result shows that even if more risk averse growers somehow mitigated the effect of receiving fewer animals by achieving better feed conversion, the net effect on revenue is still negative. This effect constitutes the second source of the cost of moral hazard.

Table 2: Risk Aversion and Revenue

\begin{tabular}{ccc}
\hline \hline \% Distribution of $b_{i}$ & Mean $R_{i t}$ (in US\$) & Standard Deviation $R_{i t}$ \\
\hline $0-10 \%$ & 32709 & 6491 \\
$10-20 \%$ & 25087 & 5914 \\
$20-30 \%$ & 23623 & 3969 \\
$30-40 \%$ & 21227 & 3195 \\
$40-50 \%$ & 17947 & 2197 \\
$50-60 \%$ & 18408 & 5971 \\
$60-70 \%$ & 12906 & 2570 \\
$70-80 \%$ & 12651 & 3164 \\
$80-90 \%$ & 11466 & 1999 \\
$90-100 \%$ & 10995 & 1949 \\
\hline \hline
\end{tabular}

\section{Conclusions}

In this paper we develop an analytical framework for the econometric estimation of the degree of risk aversion of contract producers and carry out its empirical estimation using individual growers performance data in the swine industry. We show that the heterogeneity of growers in terms of their degree of risk aversion can be identified structurally (up to a scale) using observed performance measures. The results, independent of the scale of coefficients, convincingly show that growers are heterogeneous when it comes to 
comparing their risk aversions.

The obtained results are used to look at the cost of moral hazard associated with growers' risk aversion. We show that the costs of asymmetric information arise not only from the fact that part of the performance risk has to be borne by growers (because they have to be given the correct incentives to perform), but also from the fact that the integrator allocates different number of animals to different growers according to their risk aversions. More risk averse growers will have lower expected revenues because on average they perform worse, but also because they receive fewer animals compared to the less risk averse growers. These results were confirmed in a variety of different empirical tests.

This paper ties well to the larger literature on the provision of incentives in firms, particularly to the growing debate about the trade-off between risk and incentives, and the related literature on the determinants of contract choice. It provides a strong empirical evidence that agents risk attitudes matter for the determination of the principal-agent contractual relationships in the sense that they impose constraints on offering incentives. These results are especially valuable in light of the fact that the empirical evidence that contracts are designed to optimally trade-off risk against incentives is hardly overwhelming. 


\section{References}

[1] Allen, D.W. and D. Lueck (1992). "Contract Choice in Modern Agriculture: Cash Rent versus Cropshare" Journal of Law and Economics 35(October): 397-426.

[2] Ackerberg, D.A. and M. Botticini (2002). "Endogenous Matching and the Empirical Determinants of Contract Form" Journal of Political Economy, 110(3): 564-591.

[3] Ferrall, C. and B. Shearer (1999). "Incentives and Transactions Costs Within the Firm: Estimating an Agency Model Using Payroll Records" Review of Economic Studies, 66:309-338.

[4] Margiotta, M. M. and R. A. Miller (2000). "Managerial Compensation and the Cost of Moral Hazard", International Economic Review, 41(3): 669-720

[5] Martin, L. L. "Production Contracts, Risk Shifting, and Relative Performance Payments in the Pork Industry." Journal of Agricultural and Applied Economics, 29 (December 1997): 267-278.

[6] Paarsch, H. J. and B. Shearer (2000). "Piece Rate, Fixed Wages, and Incentive Effects: Statistical Evidence from Payroll Records", International Economic Review, 41(1):59-92.

[7] Prendergast, C. (1999). "The provision of incentives in firms". Journal of Economic Literature 37, 7-63. 